\title{
The Transformation of
}

the Ursula Frayne

Catholic College Library:

Creating a Contemporary

and Collaborative

Learning Space

Jean Parker

My name is Jean Parker and my position is the Coordinator of Library Services at Ursula Frayne Catholic College. I am a qualified teacher and have been teaching in primary and secondary schools for 10 years. In 2014, I was working at Ursula Frayne as a Year 7 Teacher and Cluster Leader when the Library Coordinator position was advertised. I had a great passion for libraries and reading which inspired me to apply for the position. I started the role in 2015 and was assigned the huge task of transforming the library space. This is the story of our journey and I hope that you find this information helpful as some of you may be transforming your own libraries.

\section{Our Context}

Ursula Frayne Catholic College is a co-educational Catholic school that caters for students from Kindergarten to Year 12. The K-6 Campus is located on Balmoral Street in East Victoria Park, 3 kilometres from the Duncan Street 
Campus (7-12) in Victoria Park. The Duncan Street Campus is located approximately 5 kilometres from the Perth CBD so we are close to the city. Ursula Frayne Catholic College is multicultural and students come from very diverse backgrounds. We perform well academically for a school of our size and socio-economic status. We also have a strong pastoral care support program for our students at Ursula Frayne.

There is a library on each campus but this presentation is focused on the library at the Duncan Street Campus - namely the Anne Parker Library. The library was named after the first Principal of the College, Anne Parker. Our library is a busy place. We have a high volume of students in the library each day as we open at 7.45am and close at $5 \mathrm{pm}$ each evening. We are licensed to hold 183 people and we would be close to that limit during each break time. It is a very social space and has been nicknamed the 'living room' of the school. Students work on laptops and study with friends as well as play games. Chess is very popular at the College and we have many Chess sets that get used frequently. We have a relatively small staff in our library for a school of our size but we have an excellent team. Each staff member has a variety of skills that they bring to the team.

\section{Creating a Vision for the Library}

In 2014, a committee was set up to review the role of the Anne Parker Library in the College. The committee was made up of a group of teachers and was led by the Deputy Principal. The committee visited a number of school libraries, analysed statistics and conducted research on the latest trends in libraries. There were a number of recommendations that came from the review. Firstly, it was evident that the library needed to become the 'hub' of the school and a meeting place for students and staff. It was deemed necessary to develop the $21^{\text {st }}$ Century learning skills of students to better prepare them for when they leave school. The library also needed to be a flexible and collaborative space. We have limited classrooms in our College so rooming can be tight and the library often acts as a 'spill-over' space. The Coordinator was to become a member of Academic Council and be part of discussions and decision making with other leaders within the school. The library needed to complement the teaching and learning programmes throughout the College and also be adequately resourced to meet the needs of students and teachers. As the IT department is located next to the library, it was found that a closer relationship needed to be created between the two teams.

I then had to interpret the review and make some decisions about what the space would include. To create a flexible space, we needed to purchase shelves on wheels so that we could move shelves around. We needed to have multi-level seating and mixed furnishings to suit the needs of students and their different types of learning styles. The service desk/circulation desk needed to be moved to the centre of the library so it would be visible for all students in the library. We had to establish a warm and inviting atmosphere, particularly as it needed to be a safe space for students who have some issues and anxieties around socialising with others. We were required to provide quality resources and personnel for students and staff. We needed to advance our use and integration of technology to align with what other schools were providing their clientele. With the increasing use 
of technology in today's society, we also understood the importance of promoting information and digital literacies. Ultimately, we knew that we needed to utilise the library space effectively to ensure that we could be a successful library. We were aware of schools that had replaced libraries with resource centres, e-centres and classrooms and we were adamant that the library was still a 'must' in a school.

Initially, we needed to conduct a mass-weed. The library resources had not been weeded in a long time and we needed to weed the outdated and irrelevant books. We then made the controversial decision to split our fiction section into genres. We conducted research into this idea and did not make the decision lightly. We decided to use the same genres as some of the public libraries so that students would see some continuity when they visited other libraries. We introduced student requests so that students were more empowered to choose the books that would be on our shelves. Our goal was to focus on customer service and to let students and staff know the types of service that the library could provide for them. The library team wanted to promote reading through exciting displays that would engage the students. We also encouraged other departments to display some of their work in the library so students could view what other classes were doing. The library also housed a set of $32 \mathrm{iPads}$ that were not being used so we promoted the use of iPads by downloading new apps and using the iPads in library classes to create Book Trailers and other fun activities.

\section{The Transformation Process}

The following photos show the transformation from the old to the new space. We noticed the whole space change with new carpet and fresh paint and how well all of the new furniture came together.

Following the transformation of the physical sense of the library, we were still keen to make changes in the way that it was operating. After much research and consultation, we decided to change to a new Library Management System - Oliver - that would operate across both campuses (we were previously on two different systems). We introduced Libguides by Springshare where we started creating Research/Topic guides for staff and students. It has been a great way to integrate all of our physical and digital resources for students. These Libguides have allowed us to promote the use of ClickView and we also subscribed to some databases from Gale. We noticed that lots of other libraries all over the world were using social media to promote reading and events so we got on board and started an Instagram account (follow us @ufcclibrary) and a Pinterest page. It was important that we continued to reflect on the initial vision for the library to ensure that we stayed focused and were achieving the goals that had been originally set. Our focus has been to promote reading through visual displays, use forward facing display shelves, pick 'holiday reads' for staff and aim to have books that the members of our community want to read. Hence, our weeding still continues. 


\section{The Future of Our Library}

I think that there are so many exciting things happening in libraries that we want to ensure that we are keeping up to date with the latest trends - even if the ideas will not necessarily suit our needs, we are still keen to know what other libraries are doing. This year one of our library staff members created a bookmark for our library and we would like to investigate the potential of creating a library brand that personalises our College libraries. We have already hosted one Makerspace expo run by the Digital Student Leaders and our aim is to purchase some products for the library and have a designated Makerspace. In my Year 8 library classes, I'll be starting some Project-Based Learning opportunities for students to continue to develop inquiry-based learning skills. We need to continue marketing our library and even expanding beyond our walls by being present across the whole College. I would still love to start a reading program for students in the Middle School as reading levels continue to drop but I am still investigating programs that are suited for secondary students as many reading programs are aimed at the primary schools. All Catholic schools in Western Australia will be launching 'Leading Lights' as a management system which may affect current library systems so we are keen to know more about the possibilities moving forward.

In conclusion, this has been our journey so far and has included some of the ideas that have worked for us. My best advice would be to know your own context so that you can create a vision to suit the needs of your community. Be willing to research and visit lots of libraries to identify possibilities for your library's transformation. I asked colleagues and other experienced librarians many questions so I would suggest that you utilise the people around you too. Be prepared to take some risks - some will work and some will not but it can be very rewarding to do something different and it pays off. We really have to 'sell' the role of the library now so that people recognise how important they are in our communities.

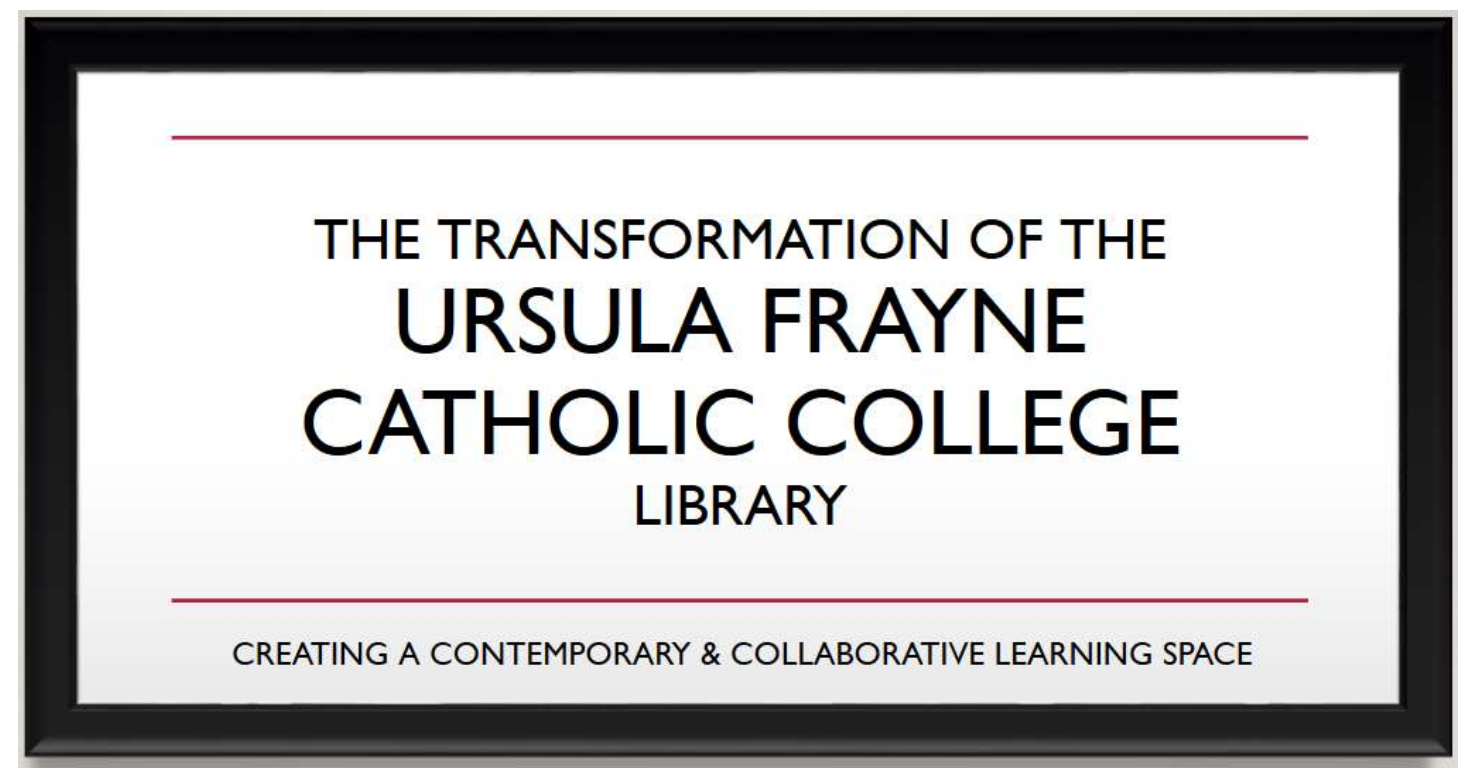




\section{THIS SESSION WILL COVER:}

- Our Context

- Creating a Vision for the Library

- The Transformation Process

- The Future of our Library

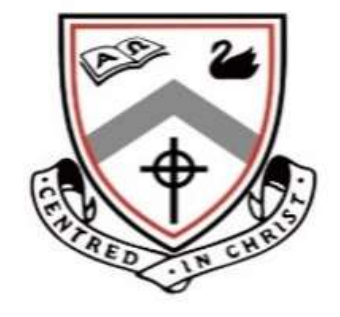

\section{OUR CONTEXT}

\section{URSULA FRAYNE CATHOLIC COLLEGE (DUNCAN ST CAMPUS) \\ US)}

7-12 Campus (approximately 850 students and 100 staff)

- Located in Victoria Park (5km from Perth CBD)

- Multicultural

- Students from diverse backgrounds

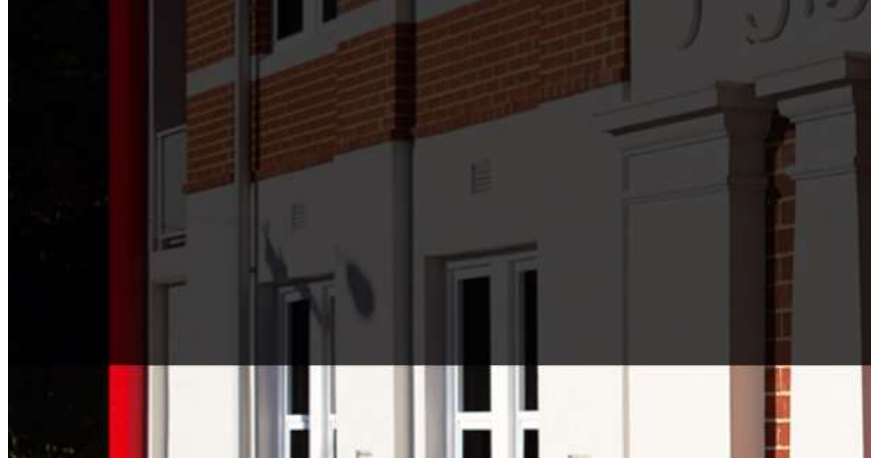

Students from dil

Students from diverse backgrounds 


\section{THE ANNE PARKER LIBRARY}

- High volume of students in the library each day (before school, break times, after school)

- Social space (games, conversations, laptop use)

- Fiction readers

- Study space

- Staffing:

- I x Teacher 5 days per week

- $2 \times$ Technicians ( 2 days each)

- $2 \times$ Officers (I day each)

\section{CREATING A VISION FOR THE LIBRARY}

\section{LIBRARY REVIEW RECOMMENDATIONS}

- Library to become 'hub' of the school

- Develop $\left.2\right|^{\text {st }}$ Century learning skills of students

- Collaborative, flexible space

- Head of Library is a member of Academic Council

- Library to complement teaching and learning programmes

- Establishment of close relationship with IT department 


\section{MY INTERPRETATION OF THE RECOMMENDATIONS}

- Shelves on wheels

- Multi-level seating

- Mixed furnishings

- Service desk in the centre of the library

- Warm and inviting atmosphere

- Quality resources

- Integration of technology

- Promote information literacy and digital literacy

\section{OUR AIM}

\section{Looks Like}

- Open-plan

- Semi-private

- Technology rich
Sounds Like

- Students collaborating, communicating and sharing

- Active participation

\section{Feels like}

- Safe

- Inviting

- Comfortable

- Modern

"The ways in which a library uses its space and resources to support the development of its community is crucial to its continuing success." -Les Watson, educational advisor, consultant on learning spaces, and editor of Better Library and Learning Spaces: Projects, Trends and Ideas (2012). 


\section{INITIAL CHANGES}

- Mass weeding

- Split fiction books into genres

- Introduce student requests

- Focus on customer service

- Promotion of reading

- 'Listening Lunches'

- Student art displays

- Promoting the use of iPads

\begin{tabular}{|c|}
\hline HUMOUR \\
\hline ACTION \\
\hline RELATIONSHIPS \\
\hline CRIME/MYSTERY \\
\hline HORROR \\
\hline FANTASYISCI-FI \\
\hline HISTORICAL \\
\hline
\end{tabular}

\section{THE TRANSFORMATION PROCESS}

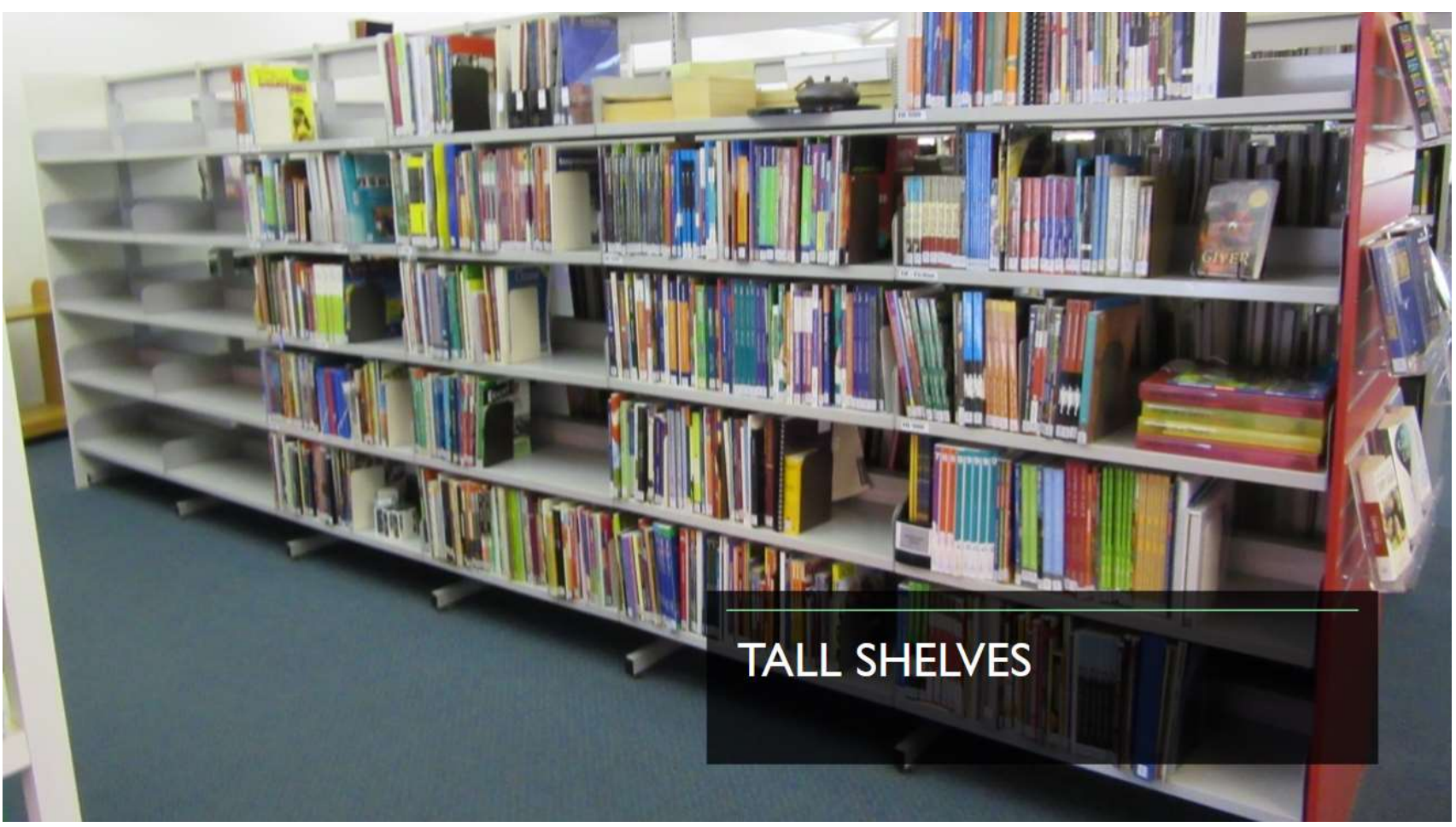



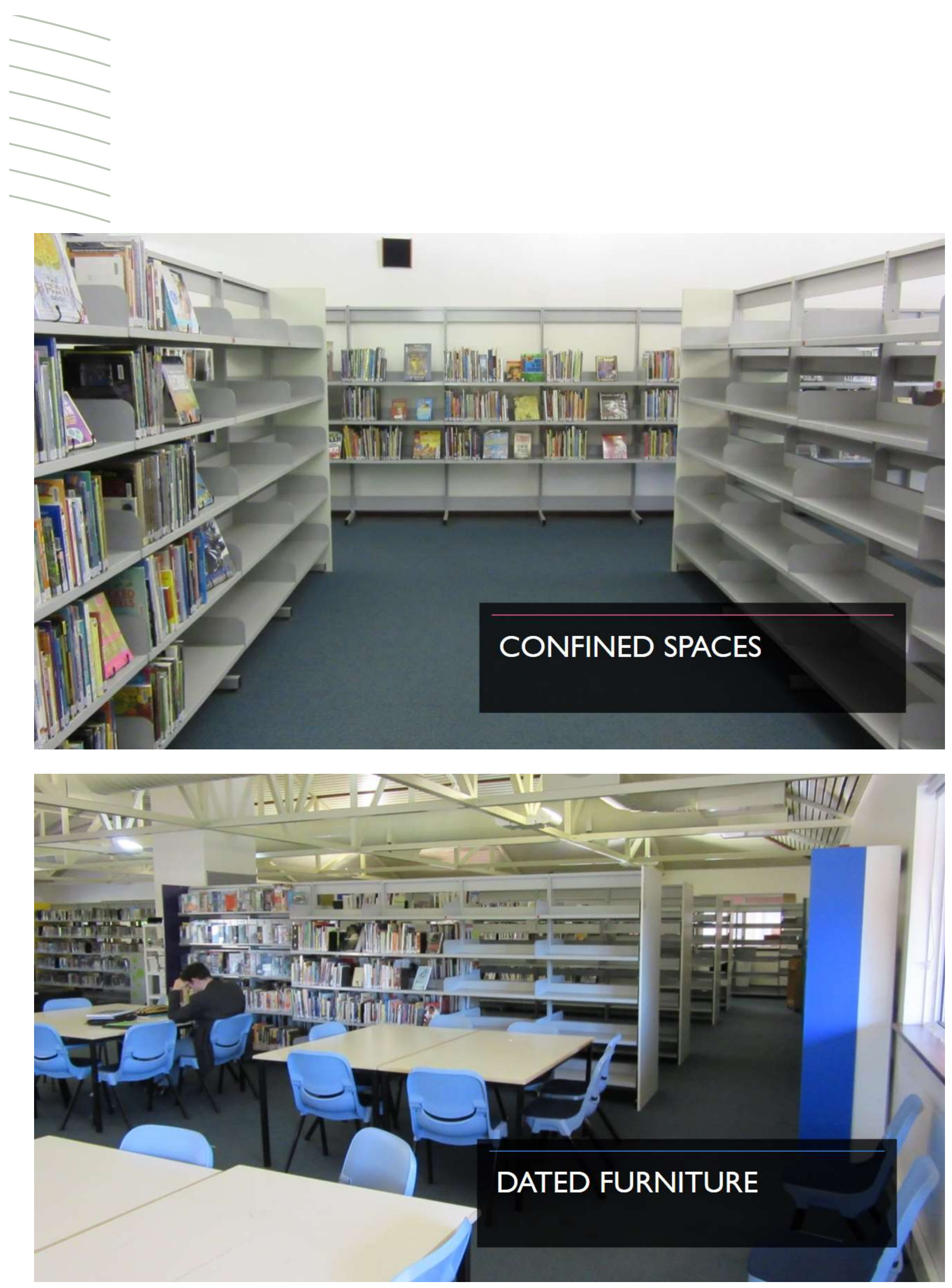

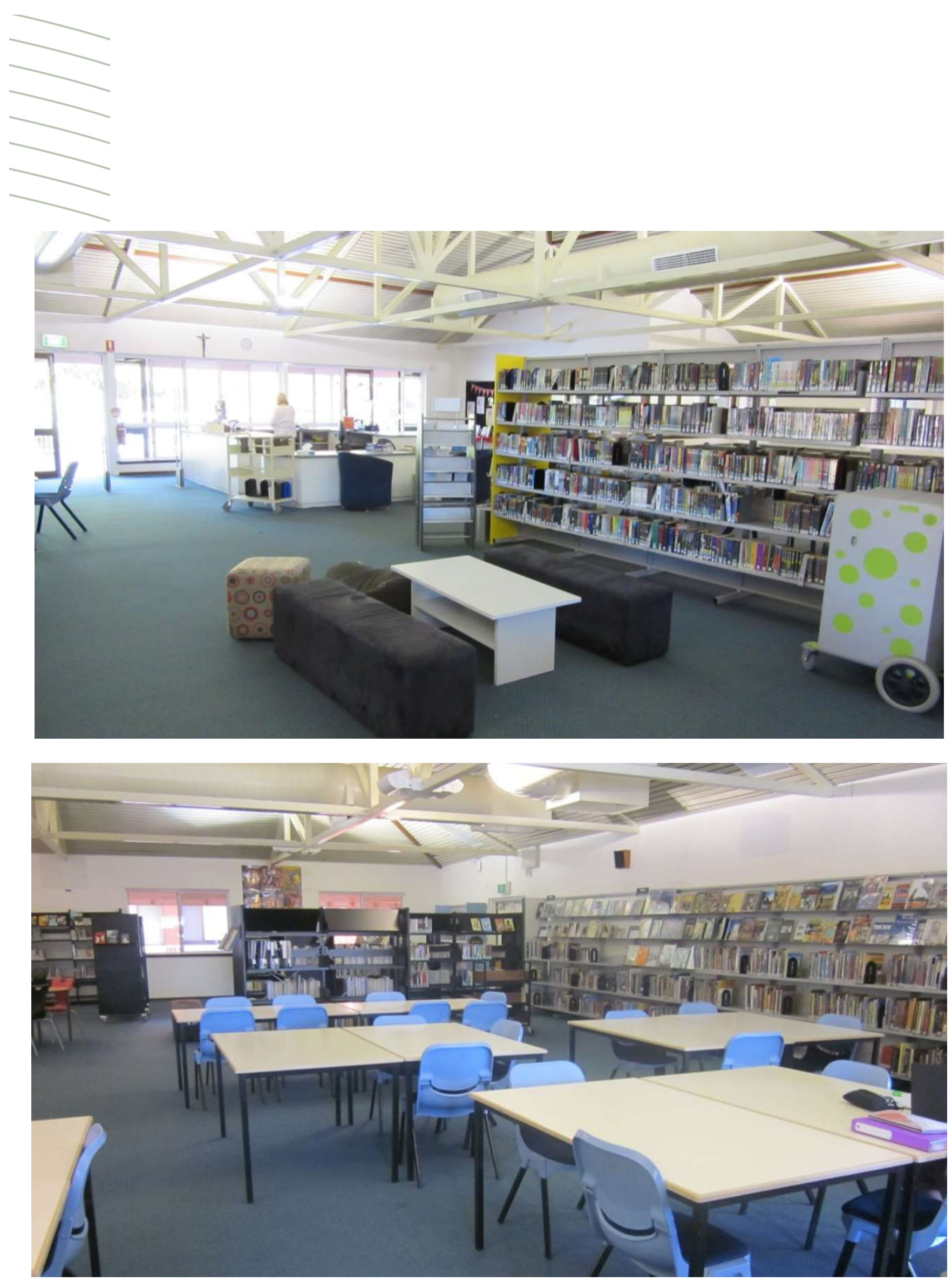

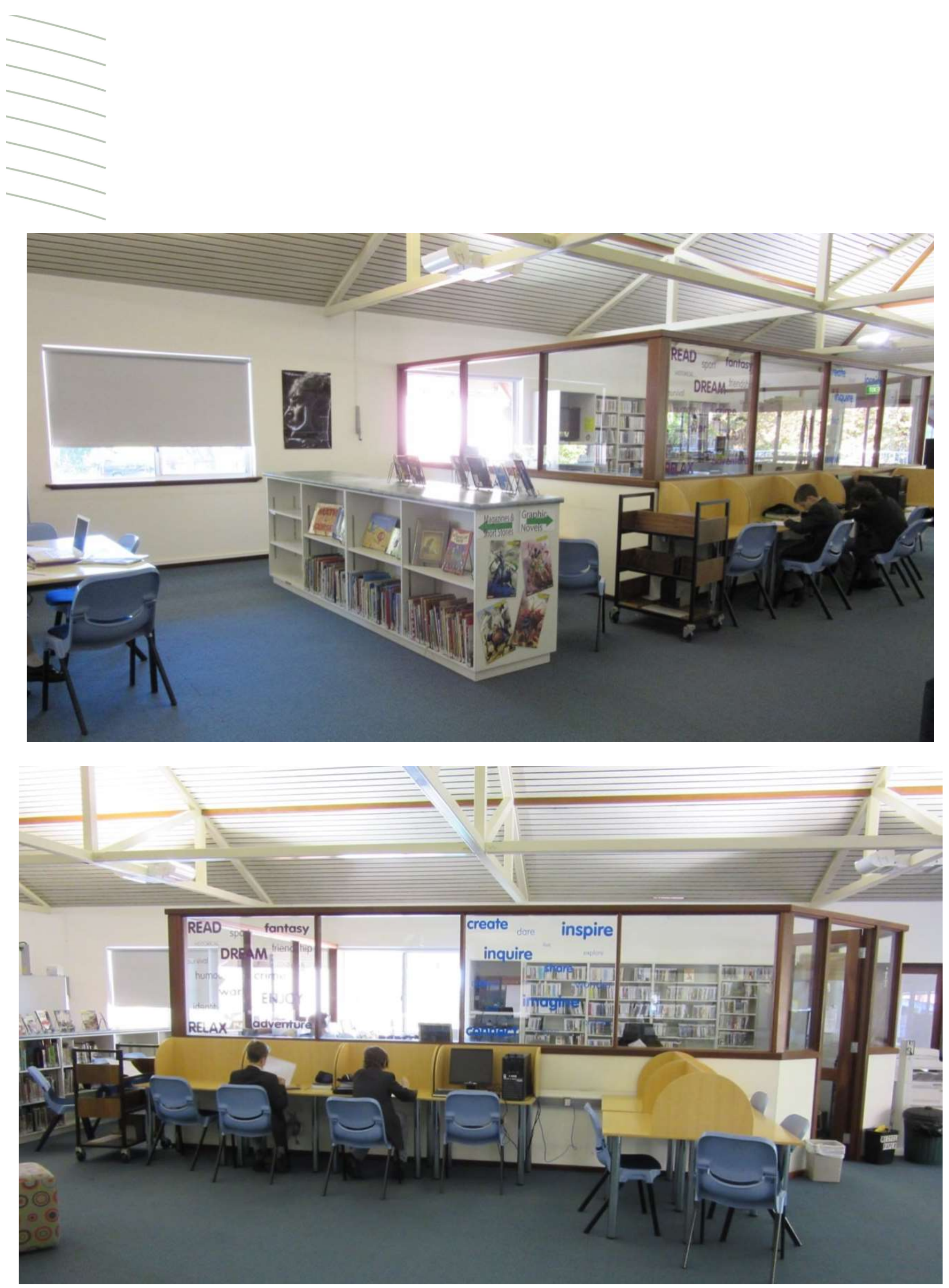

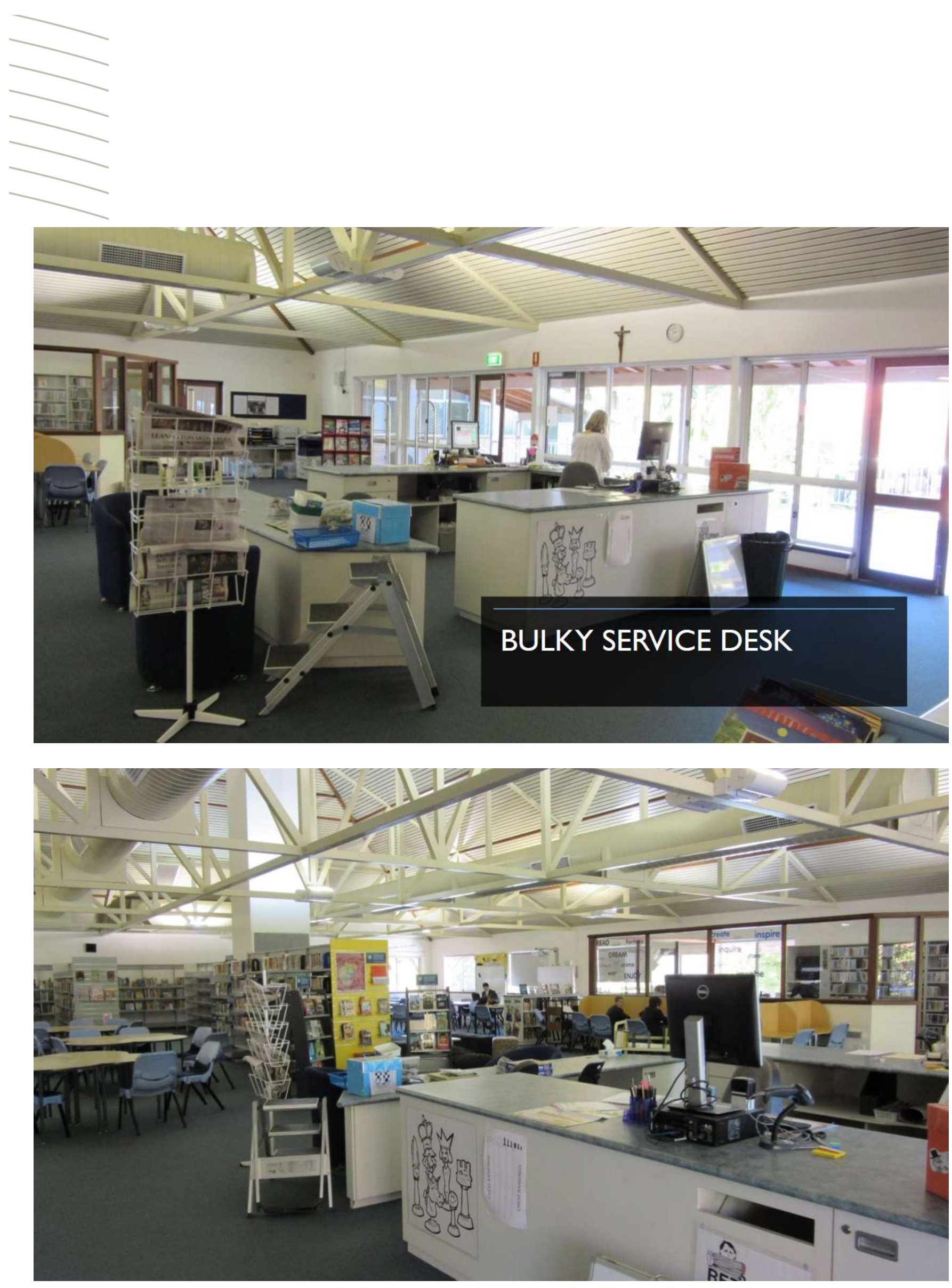

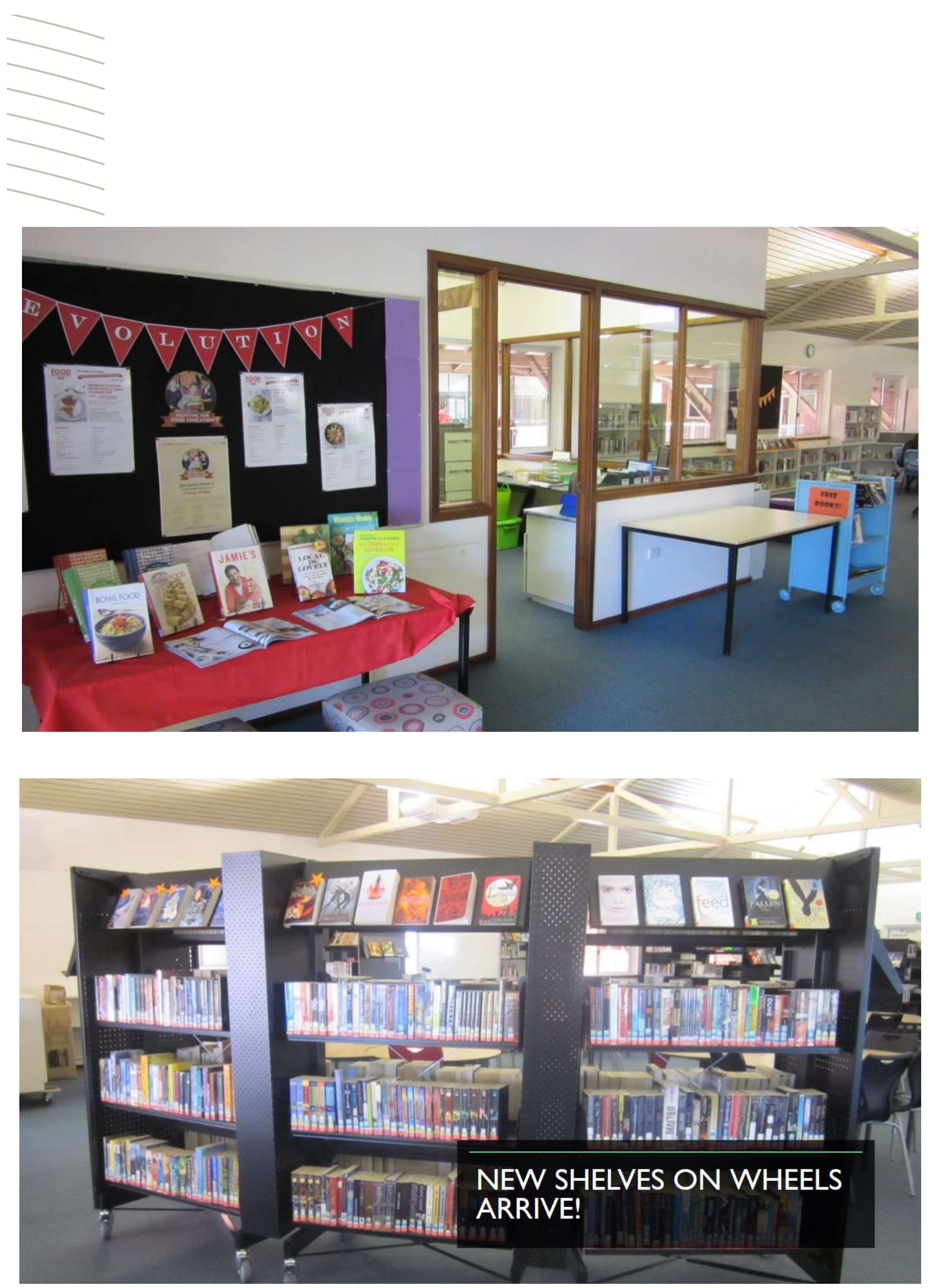

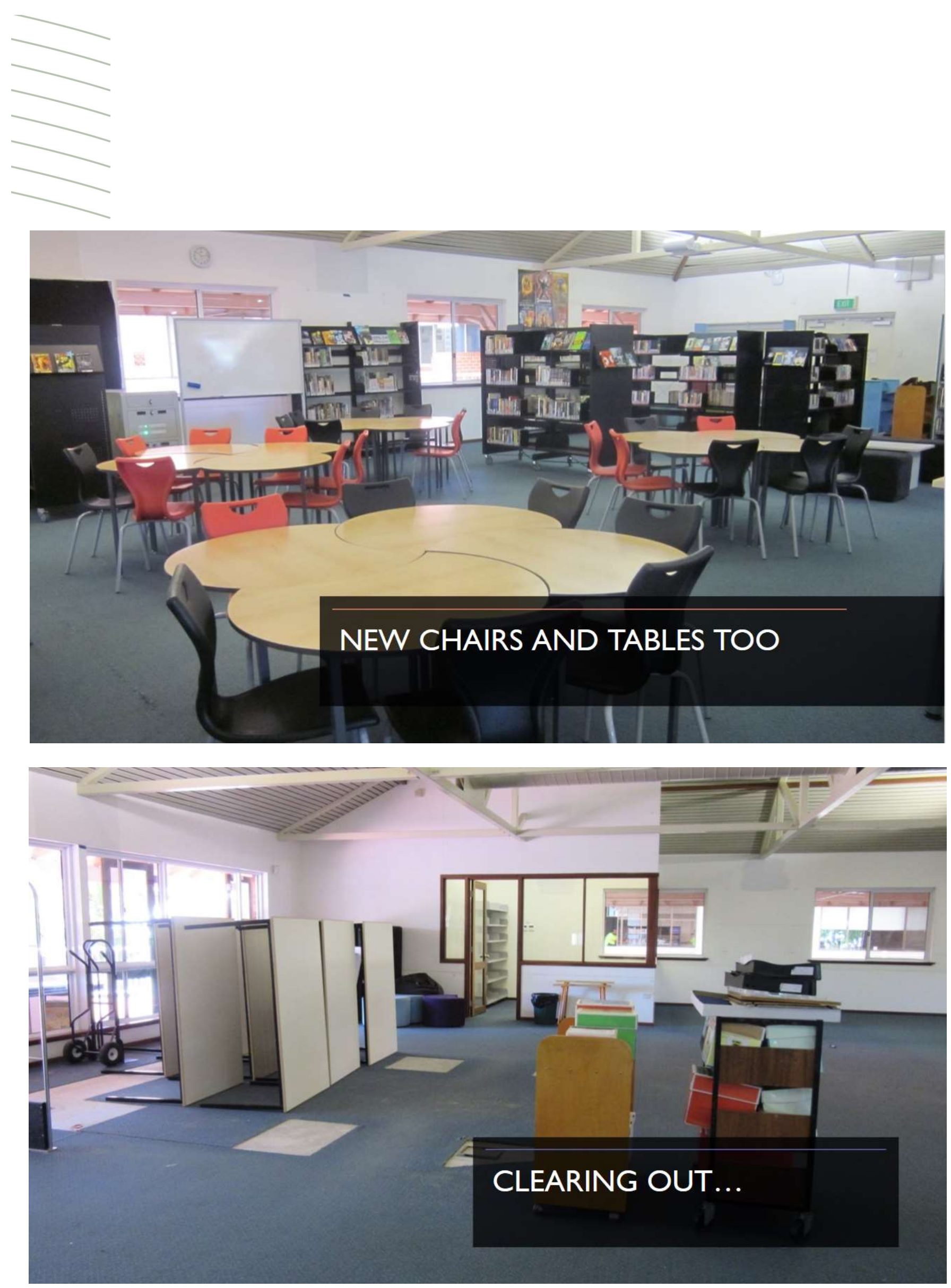

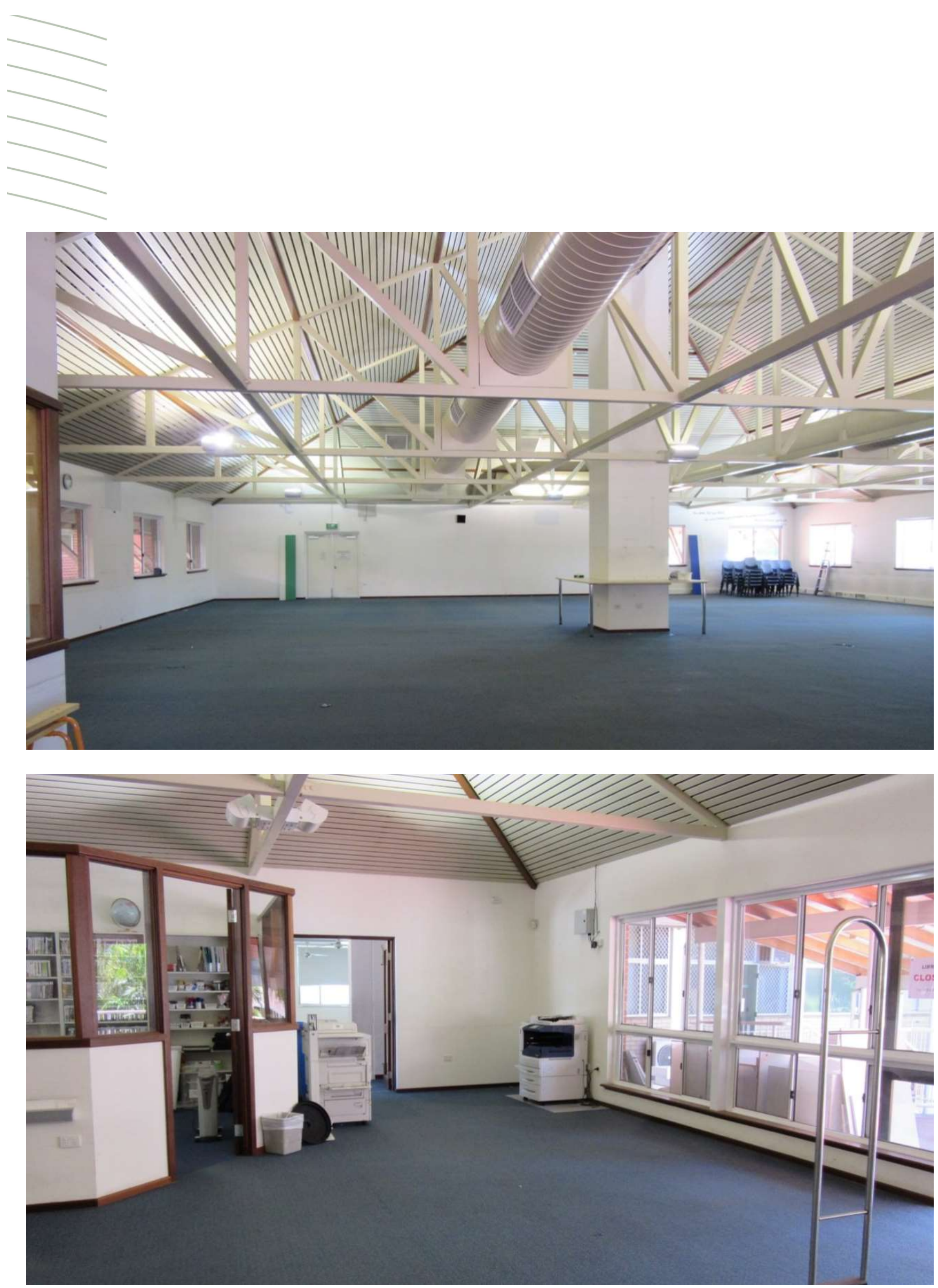

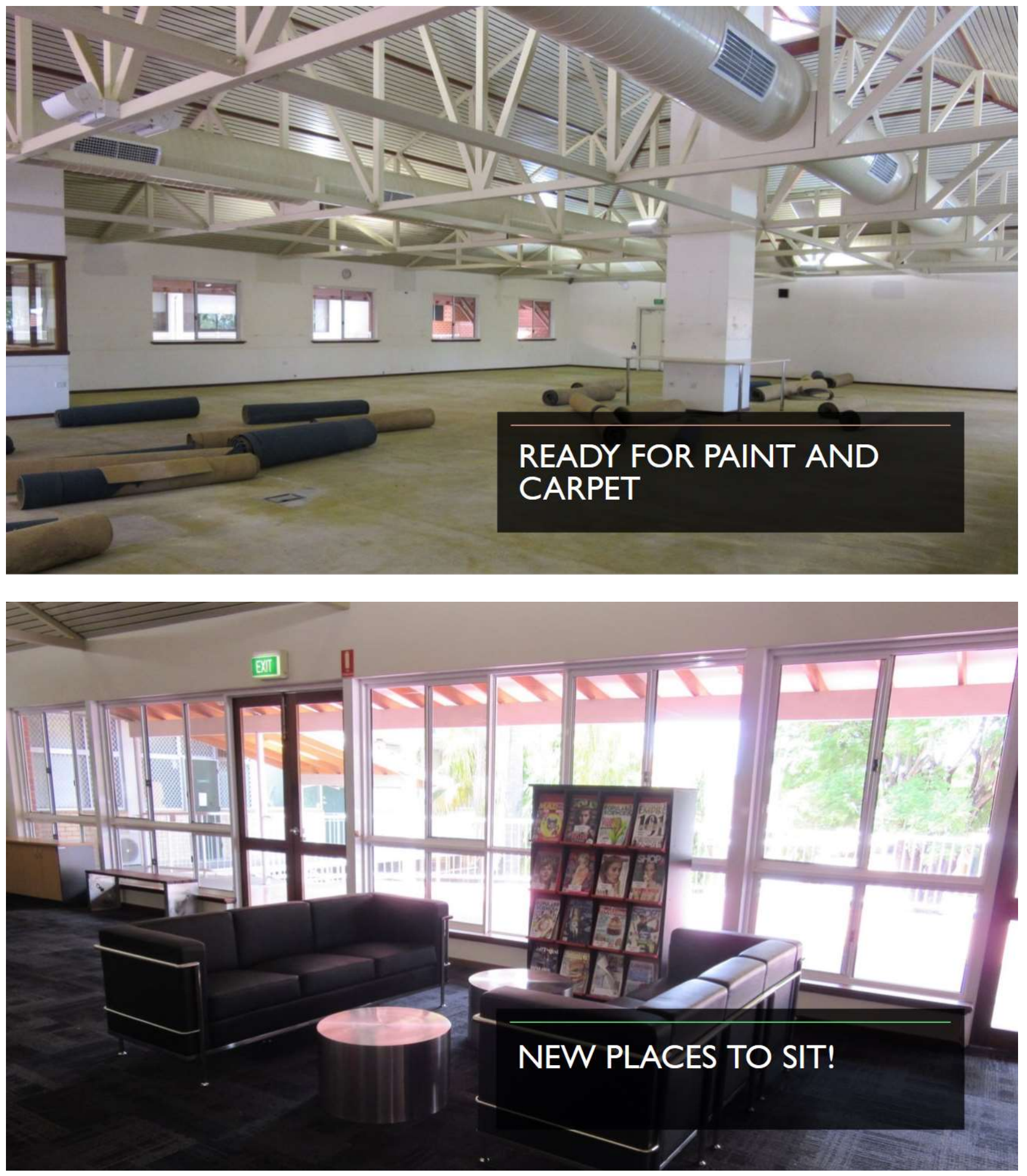



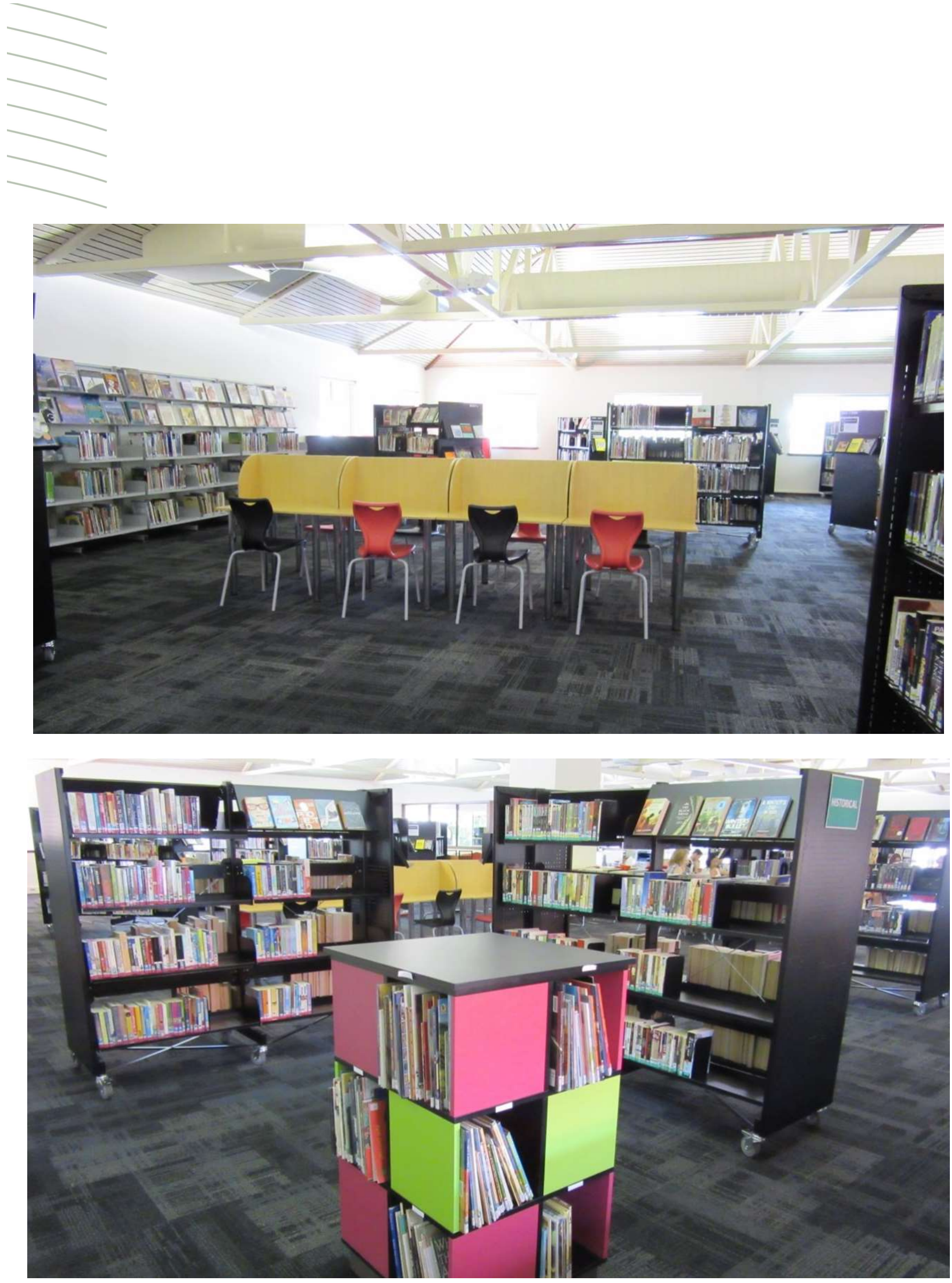

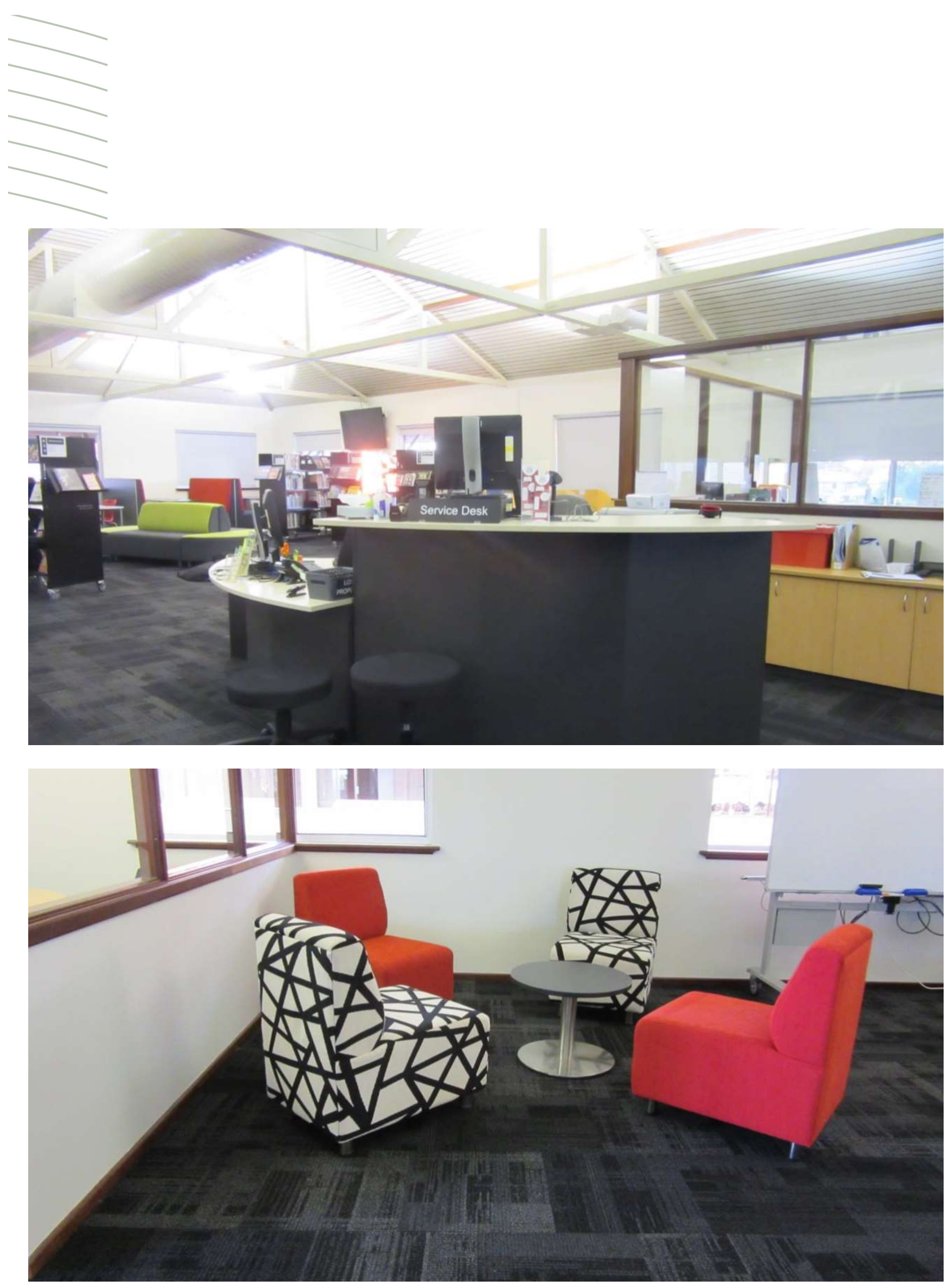

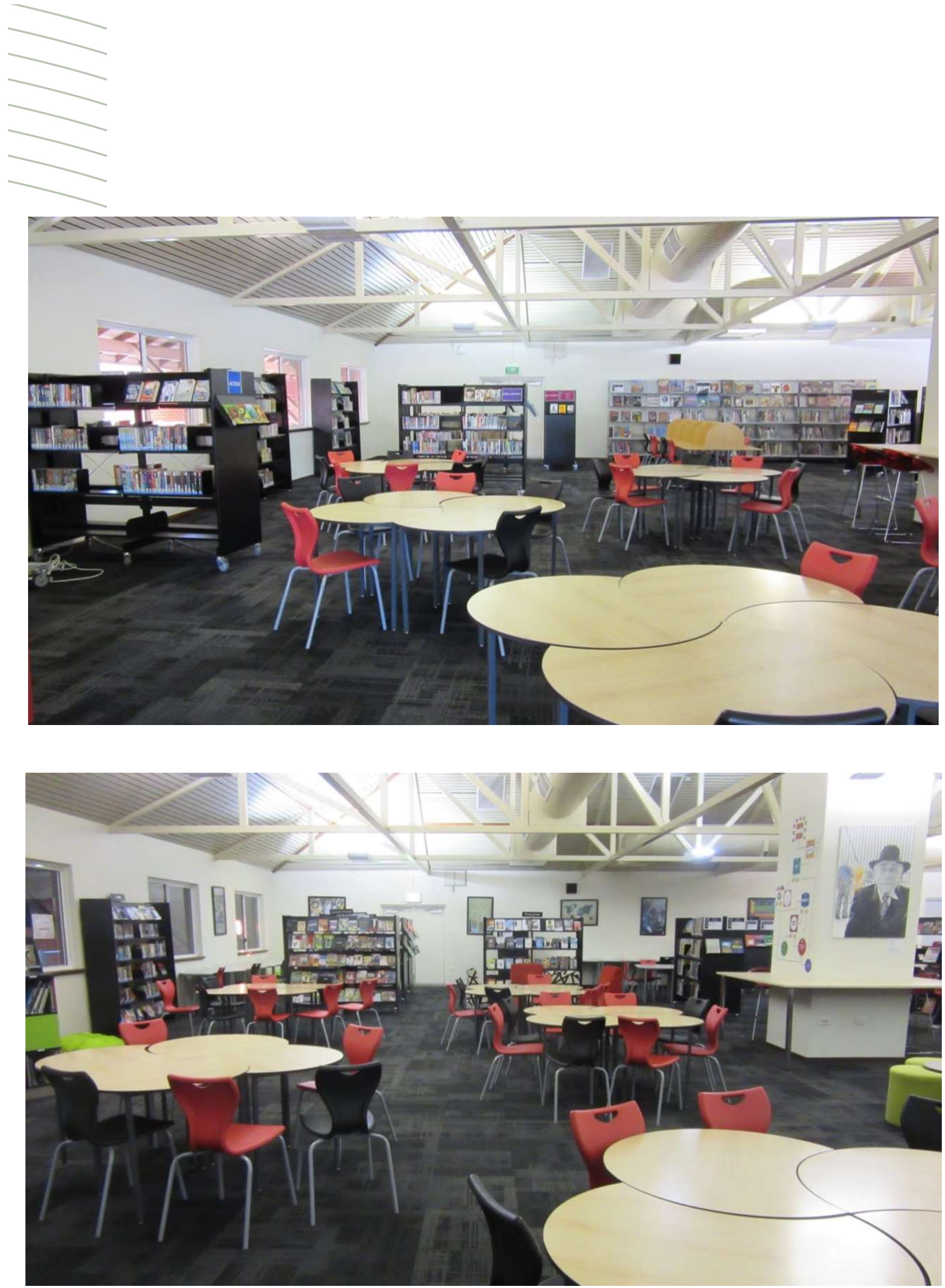
Note: (3) slides showing student faces have been removed from publication.

\section{FOLLOWING THE TRANSFORMATION}

- Change to new Library Management System for K-I2 (Oliver)

- Introduction of Libguides (Research guides)

- Promotion of ClickView

- Purchase of Databases (Gale)

- Social media (Instagram, Pinterest)

(O) Follow us @ufcclibrary
- Library displays

- Professional development of staff

- Continual reflection on the vision

- Weeding continues

- Forward facing displays

- Signage

- Promote reading to staff

\section{THE FUTURE OF OUR LIBRARY}

\section{WHERE TO NEXT?}

- Library branding

- Create a designated space for STEM project work (Makerspaces)

- Introduce Project-Based Learning to library lessons

- Develop research and referencing skills of students

- Move beyond the library walls

- Reading program

- Leading Lights?

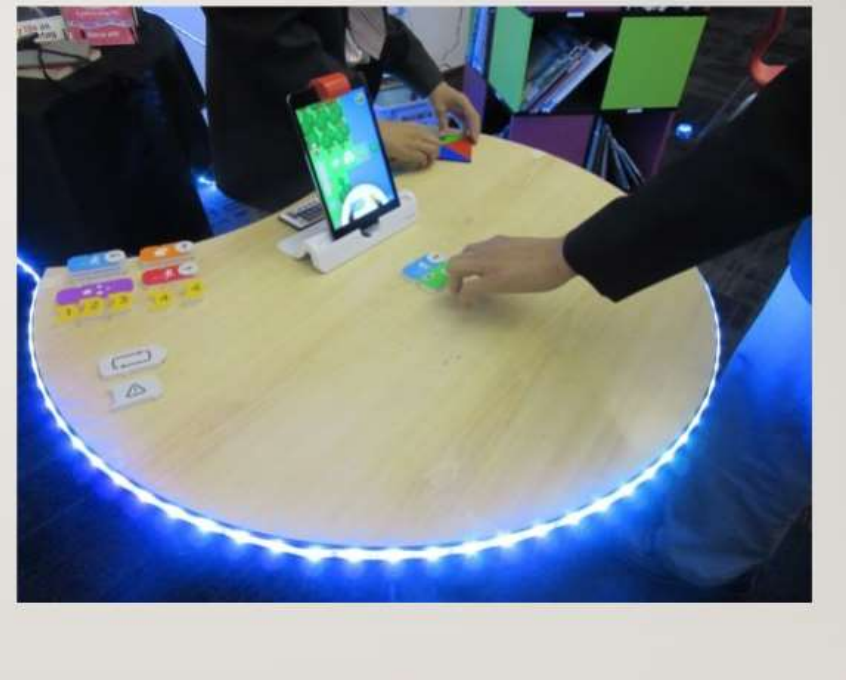




\section{IN CONCLUSION}

- Know your context

- Create a vision for your library

- Conduct research

- Learn from others, ask advice

- Be prepared to take risks

- 'Sell' your library to staff and students

- Continually reflect on the vision - has it changed?
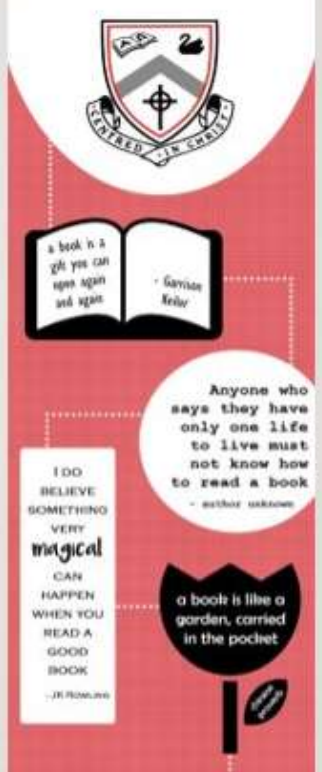

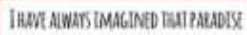
nould BE SOME KLNo of ilbuet

\section{RECOMMENDED SUPPLIERS}

- WA Library Supplies - shelving, service desk, stools

- DVA Fabrications - booth seating, casual seating, ottomans, book cube, returns trolley

- Officeline - student chairs, cupboards

- Merchandising Libraries - library signage

- Softlink - Oliver LMS

- Raeco - genre sticker labels 